\title{
Cybernetic Approach for Interdepartmental Cause-effect Relationship Modelling
}

\author{
Jonas Mayer ${ }^{*}$, Peter Nyhuis \\ Institute of Production Systems and Logistics, Leibniz University of Hanover, Germany
}

Copyright $\bigcirc 2016$ by authors, all rights reserved. Authors agree that this article remains permanently open access under the terms of the Creative Commons Attribution License 4.0 International License

\begin{abstract}
In response to a growing complexity within the value creation in companies as well as in supply chain networks, corporate decision making tasks are primarily organized in a function-oriented way. This functional orientation is inevitably reflected in departmental objectives and corresponding objective systems which define the possible optimization strategies with respect to the decision making tasks of individual departments. Based on such department-specific objective systems, the development of conflicts of objectives between departments can be observed. This paper proposes a model-based approach to create systematization for describing interdepartmental conflicts of objectives. Based on actuating variables, control variables, result variables and objectives, the objective systems and measures of individual departments are interlinked and integrated in a cybernetic model. This cybernetic model allows the description of significant cause-effect relationships between the departments in order productions. Additionally, the impacts of the decisions of individual departments on the objective systems of other departments can be derived from the model. The model as developed is restricted to the objective system of order productions but can be transferred by way of pertinent adaptations and extensions of the specific objective system to other order fulfillment processes. The transparent presentation of interdepartmental cause-effect relationships makes it possible to increase collaboration between departments. Departments are empowered in the cybernetic model to align and optimize their actions to reflect overall corporate goals and the objective systems of other departments. Furthermore, in addition to the existing empirically motivated studies, the introduced model can expand the systematic development of collaboration in companies.
\end{abstract}

Keywords Collaboration, Cybernetics, Logistic Objectives, Interdepartmental Cause-effect Relationships, Interdepartmental Conflicts

\section{Introduction}

Companies are active in a competitive environment characterized by globalization and high dynamics and face the challenge of achieving both internal corporate as well as cross corporate alignment between decision makers in a results oriented way. In this context the planning and control of supply chains are of special importance in that all decision makers involved in the production of goods must be linked together [1]. Logistics as a department represents both interdepartmental (company-internal) and company-wide cross-functions which must achieve the coordination of the respective supply chain decision makers with respect to material as well as information flows [2,3]. This paper highlights the cause-effect relationships between departments. Based on the identification of individual relationships, a cybernetic model has been developed which transparently maps the cause-effect relationships between departments. A high level of transparency of interdepartmental cause-effect relationships enables both improvements in interdepartmental coordination as well as the identification of conflicts of objectives between departments.

\section{Function Orientation within Companies as Cause of Dysfunctional Departmental Conflicts}

One result of the higher dynamics in the procurement and sales markets as well as the growing level of interdepartmental networking is a rise in corporate complexity with respect to the interdependencies between decision makers and intended objectives [4-6]. The need to deal with decision making in a complex environment is reflected in the company by way of breaking down tasks into subtasks. The functional division of decision responsibility across different departments enables the complexity of the task to be reduced [7]. This is justified in particular in that a functional restructuring of the corporation encourages distinct task specialization at a departmental level and also in 
a specification of responsibility and competence areas. Such functional division allows decision makers to take sub decisions autonomously and in part separate from one another and/or to undertake partial planning $[8,9]$. Task specializations in a department-specific fashion of this kind contemporaneous create interdependencies between individual departments $[10,11]$. These interdependencies are expressed in the form of department-specific objectives $[12,13]$ (see also Figure 1). The functionally oriented division of tasks across different departments and the consequent department-specific objectives lead to the result that within complex corporate systems a plethora of objectives are simultaneously followed. These objectives can be interdependent upon one another. An isolated optimization of department-specific objectives without consideration of the interactions with the objectives of other departments may result in conflicts of objectives (dilemmas), because in addition to the enhancing cause-effect relationships there is also the possibility of counteractive dependencies $[12,14,15]$. In this context, cross-departmental interdependencies and the resulting conflicts of objectives are referred to as the polylemma of supply chain management or logistics comprising many in part competitive objective systems. Fundamental objective systems described within the polylemma of supply chain management refer to the production, procurement and distribution logistics [8].

Dilemmas, i.e. conflicts of objectives, between departments are reflected at the corporate level in department-specific interests, territorialism, and dysfunctional departmental conflicts as well as in losses of efficiency compared with the potentially achievable optimal solution within overall planning [3,7]. In the context of growing corporate complexity, with departments being active in many, global and volatile market environments, logistics has a key role to play within interdepartmental coordination between decision makers. Logistics has to ensure that there is proper coordination with regard to the information as well as material flows between corporate departments in order to largely resolve dilemmas between departments.

Based on comprehensive experience with test subjects, Dörner[15] was able to demonstrate empirically that persons acting in complex decision making situations have a tendency to make significant mistakes. During the course of the experiments the test subjects had the task of being responsible for governing a fictional city in a computer simulation. Over the course of several rounds, the test subjects had to identify and select objective measures to further develop and evolve their city. They could take direct influence on the game result by way of complex cause-effect relationships. The scopes of the relationships were unknown to the test subjects. Dörner was able to identify the following errors: wrong objectives, unilateral focuses, tendency to oversteer and insufficient consideration of measures' side-effects. The latter point in particular is identified as the primary reason for dilemmas between departments and consequential losses of efficiency. Where cause-effect relationships are not considered between departments, a local optimization of departments takes place based on department-specific measures and objectives. Whether and to what extent the measures introduced by one department have knock-on effects on the objectives of other departments is therefore left out of consideration. The errors described by Dörner in complex situations can, however, be overcome in that the cause-effect relationships between departments are made transparent to the decision makers. The effective control or optimization of a complex system, e.g. of a company made up of many departments, is not possible if there is no awareness of cause-effect relationships.

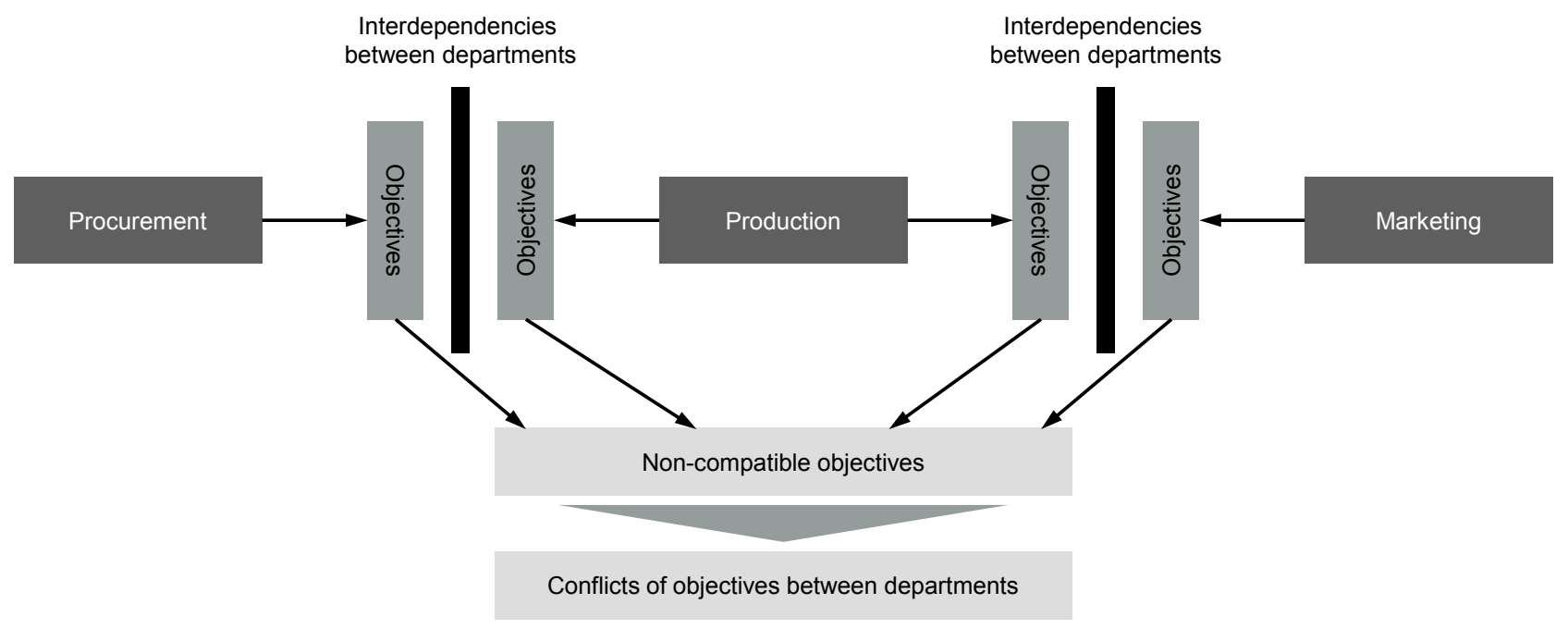

Figure 1. Interdependence-Based Objective Conflict between Corporate Departments (Based On [7]) 


\section{Literature Review of Characterized Interdepartmental Conflicts of Objective}

Interdepartmental conflicts of objective are the result of various interactions between departments (see also Figure 2). A local optimization of objectives in sales and production departments results on the one hand in unsatisfactory customer demand and on the other to high levels of finished product stocks. A possible reason for this development is in the maximization of corporate sales on the distribution side and simultaneous minimization of costs on the production side $[12,16]$. As a result of department-specific objectives, the sales department introduces rush orders, additional product variants and sales plans based on pessimistic forecasts. In contrast, production seeks to reduce production costs by increasing lot sizes and consequently reducing the number of equipment set-ups [17]. The presence of uncoordinated objectives between purchasing, procurement and sales can result in severe fluctuations in the production capacity requirements. Strategies introduced by sales require objective-compliant coordination with the upstream departments in the value chain. Therefore, an increase in delivery punctuality requires suitable supply management in order to align the sales strategy with the objectives of purchasing and procurement [18]. One of the conflicts of objectives between the planning and production departments is, for example, arising when determining the order and production lot sizes [7].

The choice between the reduced price level made possible by higher procurement quantities and the reduction of stocks in order to minimize warehousing costs may be the cause of a conflict of objective between the procurement and planning departments [19]. Interdependencies between the departments of logistics and marketing result in inefficiencies caused for example by lack of coordination concerning sales plans and sales promotion. Stank et al.[20] as well as Ellinger[21] were able to demonstrate that a close coordination between these two departments can result in an improved logistical performance of companies. In order to improve customer satisfaction and achieve a corresponding increase in sales the sales department may increase the diversity of product variants to improve the degree of satisfaction of product-dependent customer wishes. The desire of sales departments to have greater product variety as a sales boosting measure is, however, in direct contradiction to the objective of the planning department seeking to realize reduced stock levels [6]. Shapiro[22] describes key conflicts of objectives between marketing and production, such as for example conflicting objectives relating to capacity planning and sales planning as well as in the choice of a suitable product variants diversity. Based on comprehensive investigations Fawcett and Magnan[23] identified functional conflicts between purchasing and marketing departments. Dependencies and conflicts of objectives existing between the procurement, production and distribution departments were investigated by Fastabend[24] and Roesgen[8]. Zäpfel and Piekarz[25] illustrate departmental objectives and their impact on logistic systems reflecting the three corporate departments of sales, production and procurement. Wannenwetsch[2] extends this analysis with additional departments, such as e.g. quality management, controlling and service and names as the main challenge facing logistics the provision of relevant, interdepartmental information.

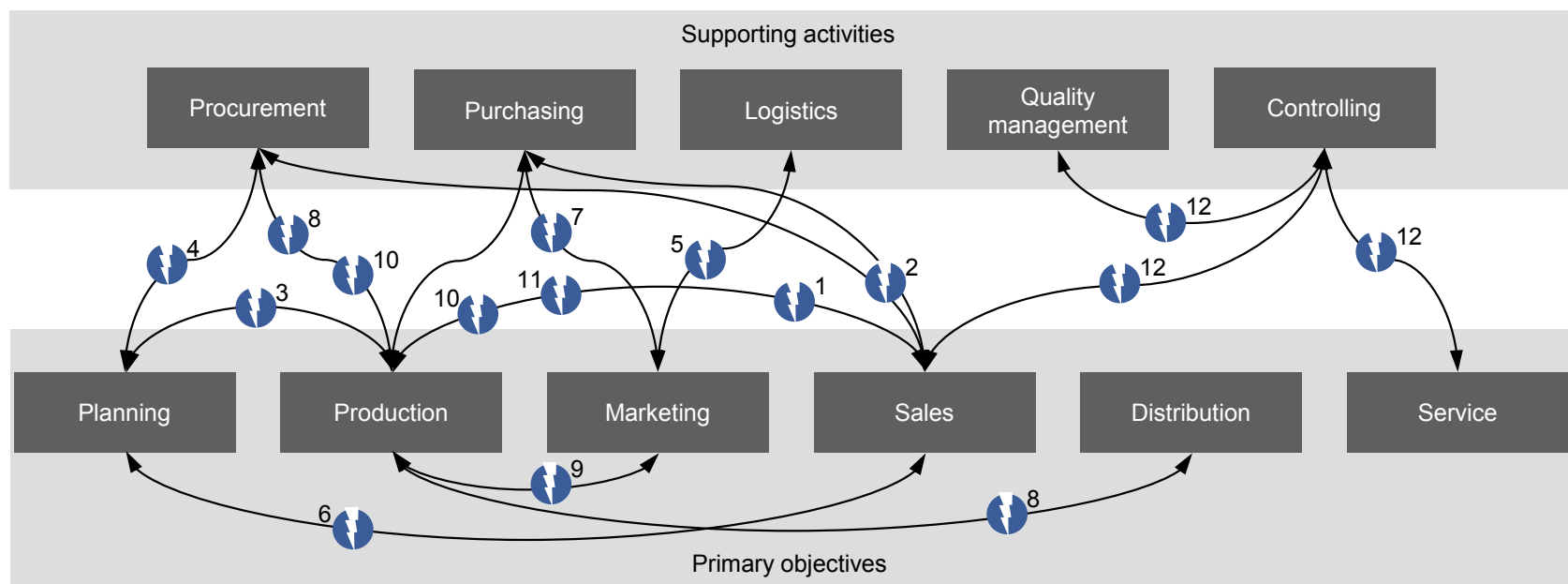

\begin{tabular}{|l|l|l|}
\hline \begin{tabular}{l} 
1: HANDY (1983) \\
\hline 2: BRETZKE (2010)
\end{tabular} & 6: GIEBMANG (2010) & 9: SHAPIRO (1977) \\
\hline 1: WEBER (1993) & 7: FAWCETT AND MAGNAN (2002) & 11: VERYARD (1994) \\
\hline 4: WESTKÄMPER (2006) & 8: ROESGEN (2007) \& FASTABEND (1997) & 12: WANNENWETSCH (2014) \\
\hline
\end{tabular}

Figure 2. Scientific Description of Conflicts of Objectives between Departments 


\section{Collaboration as a Measure to Dissolve Interdepartmental Conflicts}

As a direct consequence of the conflicts of objectives listed between departments, efficiency losses may occur compared with the optimal solution resulting from the holistic planning of all department-specific decisions [7]. The comprehensive details with respect to the discussed conflicts of objectives between departments of a company show which areas of tension are generated through the conflicts and the potential represented by resolving these conflicts.

Logistics has the task, as a cross functional department, of aligning the interdependencies between departments within the scope of holistic coordination [3]. One possibility of implementing these cross functions by way of logistical processes is to encourage collaboration between departments [26]. Collaboration in the sense of logistics is understood as collaboration between two or more departments (internal collaboration) or between two or more companies (external collaboration), in order to exchange information or resources, come to common decisions and to seek to achieve common objectives [27,28]. The impact of a lack of external collaboration in supply chains is comprehensively illustrated by the bullwhip effect $[29,30]$. Due to the lack of coordination and having no interchange of information in customer-supply relations, the bullwhip effect describes the increasing extreme fluctuations of demand levels in directions opposing the value adding process, the growing likelihood of supply delays and the consequent need to maintain higher stock levels. Possible results of closer collaboration may include increasing revenues, reducing costs, and achieving higher operative flexibility in order to respond to fluctuations in demand [30,31]. Against the background of a systematic development of collaboration between decision makers, it is necessary to shape the dimensions of cooperation, coordination and communication [32]. These three dimensions can be influenced by way of collaborative measures [33]. In the course of cooperation, key measures are boosting interdepartmental cooperation and transferring responsibilities to employees. Coordination covers the consideration of an overarching system of objectives by all decision makers as well as bundling of resources across all decision makers. Communication as the third dimension of collaboration includes the exchange of information between decision makers and the full consideration of knowledge existing amongst them.

Previous research activities relating to the description of internal collaboration between departments of a company have primarily been based upon empirical or simulated investigations. For example, the effects of information exchange between departments, the importance of having a high internal and external collaboration on logistical performance based on empirically supported investigations as well as the possibilities for measuring the degree of collaboration between departments and companies have been thoroughly analyzed [27,34-37]. The results of existing research allow the conclusion to be drawn that collaboration between departments leads to a company's improved operative performance $[27,35,38]$. In this context the key influential factors of a holistic interdepartmental collaboration can be described as the willingness to cooperate, an objective-based understanding between different departments, the exchange of information as well as resources and having common, interdepartmental objectives [27].

\section{Development of a Cybernetic Model to Describe Interdepartmental Cause-effect Relationships}

The previous elaborations have demonstrated that coordination between the different and in part contradictory objectives of departments within a company is absolutely vital in order to improve collaboration between departments and hence the company's logistical performance. The divergence of objectives between the departments is reflected in conflicts of objectives. Interdepartmental decision coordination with respect to the impact of department-specific objectives is rarely observed due to the lack of collaboration in practice. It is rather the case that the decisions of departments are investigated and optimized with respect to their impact on the department's internal objective system. To date, there is no model available to achieve a comprehensive mapping of the cause-effect relationships and dependencies between departments as well as the quantitative relationships between departments and their respective decisions. In particular, the question arises as to how a decision in one department impacts on the objectives of other departments; this can be only inadequately analyzed using existing approaches and models, since thus far only singular cause-effect relationships have been investigated between individual departments (see also section 2).

\subsection{Systematization of Logistical Cause-effect Relationships}

In the following section, a model is described based on cybernetic modelling which enables a systematic description of logistical cause-effect relationships between the objectives of different departments within a company. In this context, the model depicts the company departments and objectives for the order fulfilment process of order productions. The systematization of the logistical cause-effect relationships between departments and their respective objectives is based on actuating variables, control variables, result variables and objectives which are brought into relation to one another (see also Figure 3). 


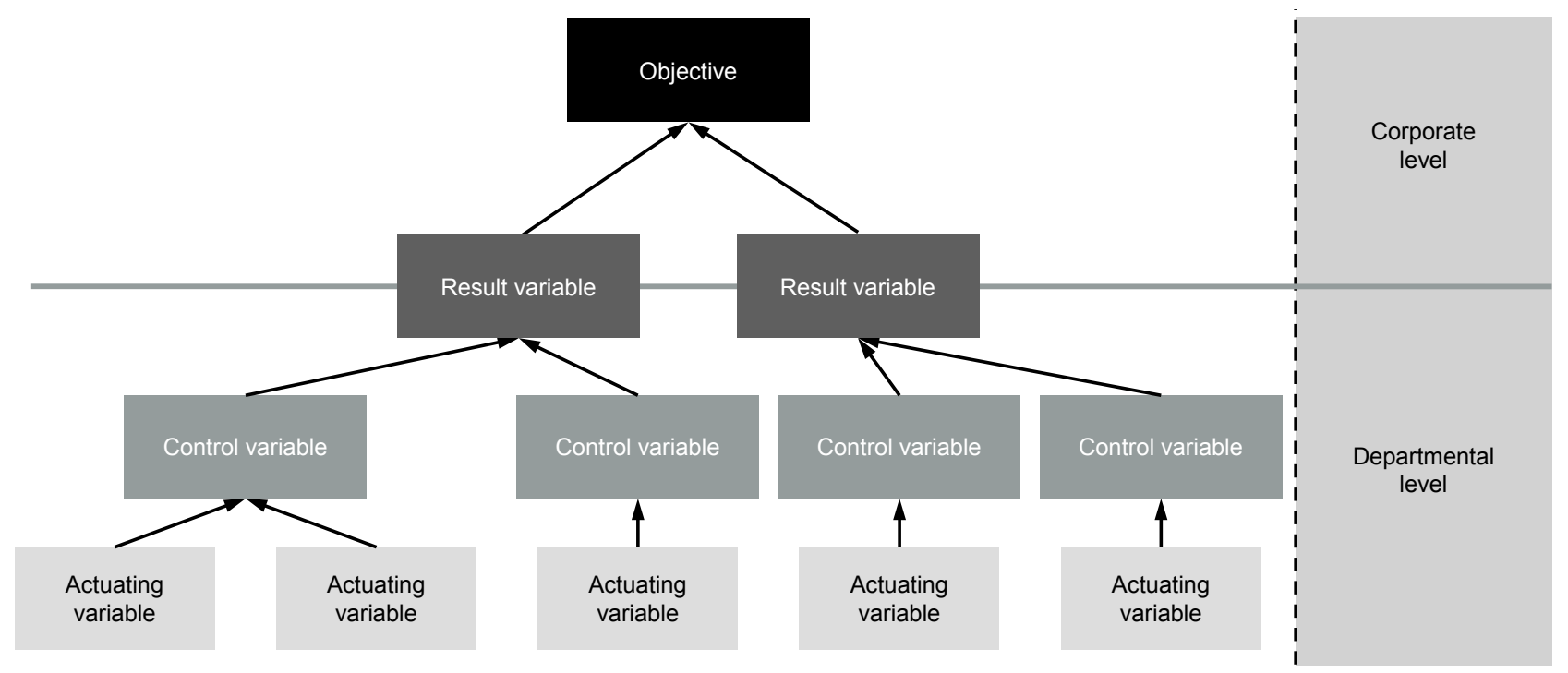

Figure 3. Hierarchy of Actuating Variables, Control Variables, Result Variables and Objectives

In the model as developed, the actuating variables represent measures which are initiated and influenced by a specific department. The decision by a department to change an actuating variable has knock-on effects in the first step on control variables. Both the actuating and the control variables of a department represent department-specific variables. In accordance with each respective department optimizing its objectives, each department uses the actuating variables at its disposal to optimize the influence on the control variables. In the sense of a department-internal cause-effect relationship, actuating variables therefore have a direct influence on the control variables.

Following the description of the department-internal cause-effect relationships between actuating and control variables, the study then includes interdepartmental cause-effect relationships. Based on the control variables which can be influenced by the departments, it is possible to influence the interdepartmental result variables. Result variables are formed by the combination of multiple control variables. Based on the definition of result variables, their respective control variables are influenced by a minimum of two different departments, because otherwise they would represent control variables not linked to any interdepartmental cause-effect relationship. By adjusting the actuating variables, the control variables of a department are influenced, whereby on the other hand the result variables allocated to the control variables are also influenced. Consequently, in an interdepartmental cause-effect relationship, actuating variables have an indirect impact on the result variables. Some interdepartmental cause-effect relationships do not include control variables. In these cases, actuating variables directly influence result variables.

Finally, the cause-effect relationships between the actuating, control and result variables on the one hand and the objectives on the other are introduced. Objectives represent the goals the company wishes to achieve as well as the overarching objective system applicable to all departments. By direct and indirect cause-effect relationships, the objectives of a company are influenced by the actuating, control and result variables. The result variables and objectives have a direct relationship with one another, such that objectives are the outcome from the interaction of several result variables. Departments then use the respective actuating variable to have an indirect influence on the objective via control and result variables. It is therefore the case that there is a causal chain in place between actuating variables, control variables, result variables and objectives which enables the continuous mapping of the dependencies between departments. Moreover, the schematically described causal chain enables the derivation of department-specific measures to influence their specific control variables and the depiction of impacts on overarching result variables and objectives in order to develop a systematic description.

The main purpose of any company is in achieving the corporate objectives as set. These corporate objectives are defined by the management and reflect the fundamental alignment of the corporate strategy. Having a hierarchical substructure allows the corporate objectives to be subdivided into overall objectives and sub-targets $[39,40]$. Taking the modelling of interdepartmental cause-effect relationships as the backdrop, overall objectives are represented by the objectives at a corporate level and the sub-targets by control variables at a departmental level. In accordance with the overarching corporate objectives, any decisions must be made in the sense of a holistic optimization of overall objectives. In turn, departments attempt to influence the department-specific control variables by way of planning and control of the measures available to such department. Due to the lack of coordination, departments will achieve local optimizations based on their measures. Whether such decisions will result in an overall optimization with respect to the overarching overall objectives of the company is not taken into account by the departments. This argument is 
based on the lack of collaboration between the departments and their divergent systems of objectives. Only in the event that knowledge of the cause-effect relationships between the departments' actuating variables exists with respect to the relevant control and result variables as well as the objectives of the corporation is it possible to align the decision making within the departments to the overall objectives of the company. The model which is described in more detail in the following is intended to achieve a greater understanding of the interdependency of decisions between departments in order to make a contribution towards improved collaboration within companies with respect to the interdepartmental coordination of objectives and the measures upon which they are based.

\subsection{Development of a Cybernetic Model}

The cybernetic model for a systematic description of interdepartmental cause-effect relationships is made up of 8 departments, 9 actuating variables, 7 control variables, 10 result variables, and 3 objectives. Sales, revenue and profit represent the three objectives implemented in the cybernetic model. The 8 departments, which are integrated in the cybernetic model, can each influence one or more actuating variables, which in turn influence the control variables of the departments (see also Figure 4).
The relationships depicted in Figure 4 emphasize that various departments can influence the same control variables by way of their different actuating variables. In this, the actuating variables can have both a positive or negative influence on the control variables. As an example, production control is able to both influences the variation of schedule deviation within production as well as the productivity by adjusting the sequence value (e.g. by changing from a schedule-oriented to a set-up time-optimized sequencing rule). A set-up time-optimized sequencing rule results in an increased variation of schedule deviation within production. At the same time, it achieves reductions in set-up costs and hence impacts the productivity. The company departments of planning and design are able to influence the productivity within production by adjusting the lot size or by changing variant diversity. Accordingly, three departments have a direct influence on the productivity. If there is no direct coordination between these departments, it is possible that the measures undertaken by one department compensate the measures of other departments. This could mean that there is no change to the control variable productivity although measures were undertaken to achieve this effect. Further relationships taken into account in the cybernetic model between departments, actuating variables and control variables are presented in Figure 4.

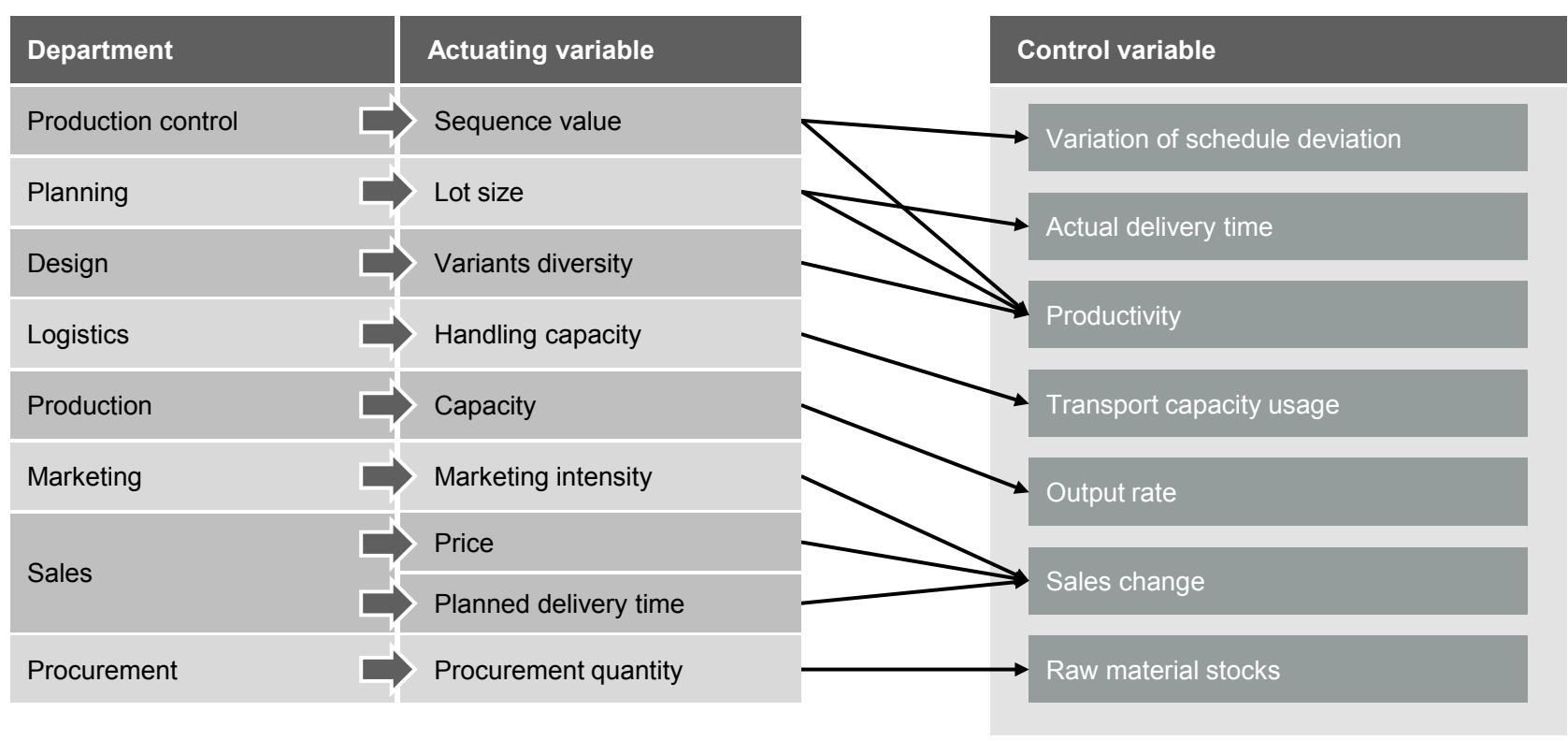

Figure 4. Dependencies between Departments, the Specific Actuating Variables and the Influenceable Control Variables 
In a further step, the departments, actuating and control variables summarized in Figure 4 are interlinked in a cybernetic model (see also Figure 5). In the following, the result variables and objectives implemented in the model are described in more detail and the modes of influence represented by the actuating and control variables are presented. Deviations in delivery time result from the difference between the control variable "actual delivery time" which is influenced by the control variable "lot size" in the planning department and by the actuating variable "planned delivery time" in the sales department. The result variable "output quantity" (output of production) is determined both by the control variable "productivity" and by control variable "output rate" within the production department. The planning (actuating variable "lot size"), production control (actuating variable "sequence value") and the design (actuating variable "variant diversity") departments can exert influence on control variable "productivity". Productivity can be increased by the planning department via an increase of the actuating variable "lot size", by the production control department through a set-up optimized change of the actuating variable "sequence value" and by reducing the "variant diversity" of products in the design department. The control variable "productivity" and the result variable "output quantity" have a proportional relationship. In addition to influencing the control variable "output rate" by way of providing production capacities by the production department (actuating variable "capacity") the result variable "material availability" also has a direct influence on the output rate. Value added performance in the production department is only possible by having simultaneous availability of production capacities as well as raw material stocks.

The departments of procurement and logistics are able to control the result variable "material availability". The procurement department can either raise or reduce the "raw material stocks" by changing the "procurement quantity". Simultaneously, the "procurement quantity" also influences the result variable "handling effort" which is a key parameter for the control variable "transport capacity utilization". The control variable "transport capacity utilization" is also determined by the "handling capacities" availability. This actuating variable is the responsibility of the logistics department.

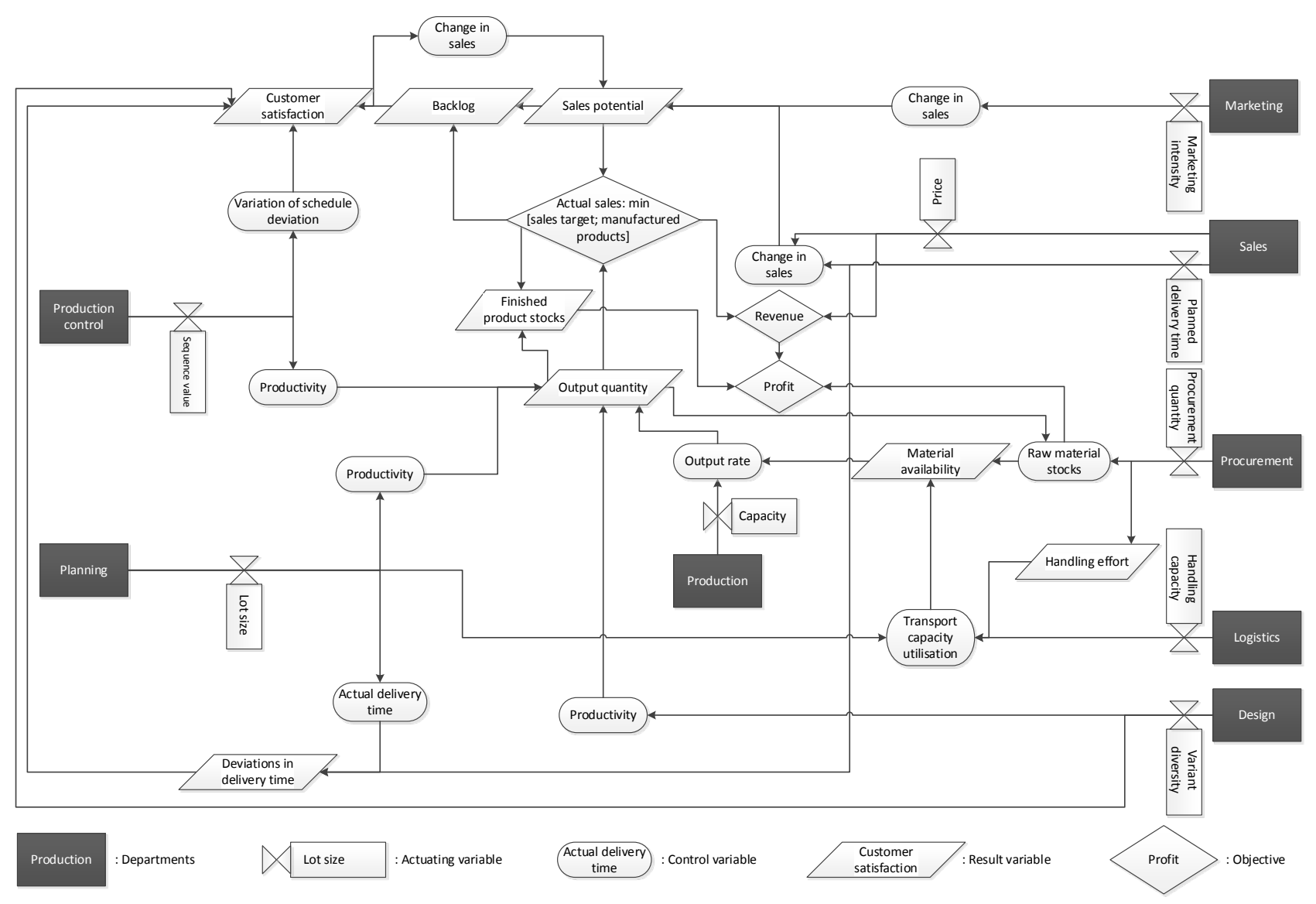

Figure 5. Cybernetic Model of Actuating, Control and Result Variables As Well As Objectives within the Structure of Order Productions 
The result variable "sales potential" represents the market volume and is influenced by the marketing and sales departments. The marketing department can change the actuating variable "marketing intensity" to influence the level of awareness of the company as a whole. This can produce positive or negative changes in sales depending upon whether "marketing intensity" was raised or lowered. Furthermore the sales department can use the actuating variables "price" and "planned delivery time" to influence the control variable "sales change". The lower/higher the "price" and/or the value of the "delivery time plan" are set, the higher the level of induced positive/negative sales change.

The interdepartmental objective "actual sales" is derived by comparing the result variable "sales potential" and "output quantity". If the "output quantity" is larger than the "sales potential", then the variable "actual sales" corresponds with "sales potential". The excess "output quantity" is summarized in the result variable "finished product stocks". In the event that the "output quantity" has a value lower than "sales potential", then "actual sales" is exactly the same as "output quantity". The difference between "actual sales" and "sales potential" is summarized in the result variable "backlog". In the event that "sales potential" corresponds with the variable "actual sales" then the variable "backlog" is zero. In the case that "actual sales" is smaller than "sales potential", then the market-generated customer demand could not be fully satisfied such that there is a "backlog" on the customer order side. The actuating variable "variant diversity" of the design department has an influence on the result variable "customer satisfaction" as does the "variation of schedule deviation", a control variable in production control department, the result variable "backlog" and the "deviation in delivery time", which is a result variable of the planning and sales departments. Accordingly, logistical performance features (variation of schedule deviation, delivery time deviations and order backlogs) as well as product configurations have a direct influence on the level of customer satisfaction. The result variable "customer satisfaction" has an influence on the result variable "sales potential" by way of a feedback mechanism. Reflecting the high importance of logistical performance on the market side (see for example [41]), it is concluded that in addition to the product features (price and product design) in particular the logistical performance features are reflected in the market-side result variable „sales potential“".

Creating a link between the sales' actuating variable "price" with the objective "actual sales" generates the second objective "revenue". In the cybernetic model the "profit" represents the primary objective. This objective represents the objective "revenue" reduced by the value of finished products and raw material stocks.

\subsection{Deriving Cause-effect Relationships between Actuating Variables, Control Variables, Result Variables and Objectives}

Having derived the basic relationships between the actuating variables, control variables, result variables and objectives in the cybernetic model as developed, in a next step the cause-effect relationships are specified between the individual variables. Within the context of this paper, principal cause-effect relationships are described qualitatively. Based on diagrams, which depict the influence of cause variables (shown on the $\mathrm{x}$-axis of the diagrams) on the resulting variables (shown on the y-axis of the diagrams), the cause-effect relationships located within the cybernetic model are further detailed, while examples of function profiles are presented in order to describe the interdependencies between the individual variables (see also Figure 6).

Increasing the sales while maintaining the same price level or achieving price increases whilst maintaining a constant sales level both result in higher profit. On the cost side, the raw material stocks and finished product stocks have a negative impact on profits, since the level of stocks increases the level of capital lockup. Sales changes with respect to the control variable "sales change" are induced by four factors. An increase in customer satisfaction and a higher level of marketing intensity both impact by increasing sales. In contrast, increases in planned delivery times and prices result in a negative sales change.

Customer satisfaction is also influenced by four variables. An increase in backlog is the equivalent in customer demand not covered by production. A decrease in customer satisfaction is to be expected if the customer demand is not $100 \%$ covered by production, since there will be larger backlogs on the customer side and additional non-planned delivery times. Having a higher level of variants diversity of finished products raises the expectation that customer needs are satisfied to a high degree on the product-side. A consequence of customer-oriented product design in the form of different product variants means that an increase in variant diversity would be reflected in a higher level of customer satisfaction. From a logistics point of view, schedule and delivery time deviations have an impact on customer satisfaction as well. Smaller deviations result in higher logistical plannability. In contrast, any increase in schedule deviations result in a deterioration of logistical performance and hence in a reduction in customer satisfaction. Delivery time deviations are determined based on comparing the planned delivery time with the actual delivery time. Positive lateness values (actual minus planned values) are equivalent to a reduced logistical performance and hence also result in falling customer satisfaction, since the delivery date promised to the customer cannot be met. Negative lateness is also reflected in falling logistical performance. Products, for which production is finished ahead of schedule, may need to be intermediately stored by customers under the applied assumption of direct delivery of 
finished products to customers. This results in higher costs on the customer side, and in turn leads to a reduction in the customer satisfaction value. Only in the case that delivery time deviations have the value zero may customer satisfaction be assumed to be high.

The output rate as a key control variable of production is influenced on the one hand by the capacity availability on the production side. On the other hand, it is necessary for raw materials to be available in order to capacitate production capacities to produce. The modeling of the cause-effect relationship between the material availability and the output rate achievable is in accordance with the theory of the logistics operating curves [42]. The productivity of production is determined by the variant diversity, lot size and the sequence value. An increase in product variant diversity is seen in a higher production process complexity. This increase in complexity results in reduced control of the production processes, hence in a falling productivity level. The set-up costs can for example be reduced by adjusting the sequence value and are described in the modeling by a productivity increase. In the event that a sequence rule is selected which offers optimal set-ups, the necessary set-up costs are reduced. A schedule-oriented sequence rule, on the other hand, impacts by reducing productivity. Similarly, lot size has an impact on productivity. An increase in productivity can be achieved by increasing lot sizes, since this measure also has the effect of reducing set-up costs and vice versa. In addition to increasing productivity, lot size also has an influence on the delivery time. There is a proportional relationship between the lot size and the delivery time. The larger the lot size is selected, the longer the anticipated delivery times and vice versa. An increase in procurement quantity results in increasing raw material stocks as well as in a higher handling effort. If the procurement quantity is reduced, the raw material stocks also fall as does the handling effort. In addition to the influence of the sequence value on productivity, a switch-over from a set-up optimized to a schedule-oriented sequence value also results in a change to the variation of schedule deviation. In this regard, the schedule-oriented sequence rule is reflected in a reduced variation while a set-up optimized rule results in a higher variation of schedule deviation.

The cybernetic modeling presented of interdepartmental cause-effect relationships between actuating variables, control variables, result variables and objectives is limited to an order fulfillment process in order productions. Depending upon which order fulfillment process a corporation implements, it will be necessary to add departments and variables, take new cause-effect relationships into consideration or delete departments, variables or cause-effect relationships from the model on a case-by-case basis. Overall, the modeling of the interdepartmental cause-effect relationships can serve as the basis for other order fulfillment processes taking into account adaptations and additions.

The model as developed and the cause-effect relationships as described are subject to simplifications and assumptions in order to limit the complexity of the cybernetic model to a manageable level. Nonetheless the model enables the interdependencies between departments to be the subject of a theoretical approach.

\section{Outlook}

Current German research effort is focused on the options and potentials offered by Industry 4.0 by way of improving collaboration between departments and companies in networks $[33,43]$. The networking of cyber-physical systems by way of Industry 4.0 will increase the interaction between decision makers and make a major contribution to increasing their reciprocal collaboration $[33,44]$. This paper provides a major contribution towards achieving systematic and comprehensive modelling of interdepartmental and intercorporate cause-effect relationships. In a next step, the interdepartmental cause-effect relationships as identified and described in this paper are transferred into an expanded quantitative description. Based on a quantitative cybernetic model it is considered possible to develop a decision making model to support the strategic alignment of departments and to derive measures for target-oriented influencing of overarching corporate objectives.

The approach of the model presented of interdepartmental cause-effect relationships provides for a transparent description of interdependences between company departments. The model allows propositions to be concluded with respect to the influence of decisions made by individual departments on other departments. Based on this information it is in particular possible for logistics, as a corporate cross-functional department, to be able to describe material and information flow-related relationships as well as coordination between departments in order to enhance collaboration. 


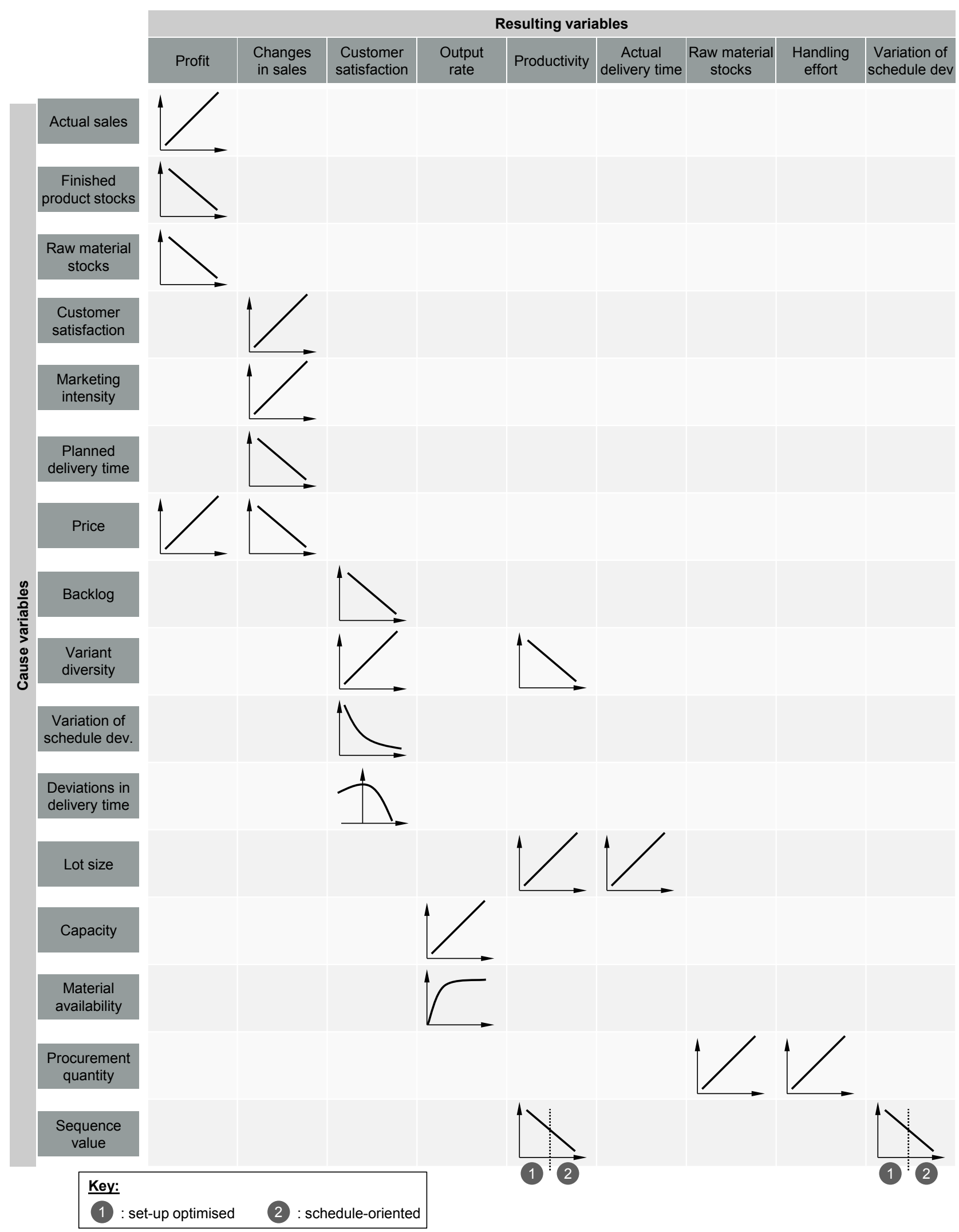

Figure 6. Modelled Relationships between Actuating Variables, Control Variables, Result Variables and Objectives 


\section{REFERENCES}

[1] P.D. Larson, D.S. Rogers (1998), "Supply Chain Management: Definition, Growth, and Approaches", Journal of Marketing Theory and Practice, Vol. 6 No. 4, pp. $1-5$.

[2] H. Wannenwetsch (2014), Integrierte Materialwirtschaft and Logistik - Beschaffung, Logistik, Materialwirtschaft and Produktion [Integrated market economy and logistics Procurement, logistics, materials management and production], Springer, Berlin Heidelberg.

[3] P. Nyhuis (2008), Beiträge zu einer Theorie der Logistik [Contributions to a theory of logistics], Springer, Berlin Heidelberg.

[4] C. Bliss (2000), Management von Komplexität - Ein integrierter, systemtheoretischer Ansatz zur Komplexitätsreduktion [Management of complexity - An integrated, systems theory based approach for complexity reduction], Gabler Verlag, Wiesbaden.

[5] R. Kirchhof (2003), Ganzheitliches Komplexitätsmanagem ent - Grundlagen und Methodik des Umgangs mit Komplexität im Unternehmen [Holistic complexity management - Basic principles and methods for complexity management in companies], Deutscher Universitäts-verlag, Wiesbaden.

[6] M. Gießmann (2010), Komplexitätsmanagement in der Logistik [Complexity management in logistics], Josef Eul Verlag, Köln.

[7] J. Weber (1993), Logistik-Controlling [Logistics controlling], Schäffer-Poeschel, Stuttgart.

[8] R. Roesgen (2007), Analyse der Nutzenpotenziale von Supply Chain Management Systemen [Analysis of application potentials of supply chain management systems], Shaker Verlag, Aachen.

[9] E. Frese, M. Graumann, L. Theuvsen (2012), Grundlagen der Organisation - Entscheidungsorientiertes Konzept der Organisationsgestaltung [Basic principles of organisations Decision-oriented concept for organization development], Gabler Verlag.

[10] A. Kieser, H. Kubicek (1992), Organisation, de Gruyter, Berlin \& New York.

[11] J. R. Galbraith (2014), Designing organizations, Jossey-Bass, San Francisco.

[12] R. Veryard (1994), Information coordination, Prentiee Hall International (UK) Limited, Hempstead.

[13] M. Christopher (2011), Logistics \& Supply Chain Management, 4th ed. Pearson Education Limited.

[14] J. G. March (1988), Decisions and organizations, Basil Blackwell Ltd, Oxford.

[15] D. Dörner (1989), Die Logik des Misslingens. Strategisches Denken in komplexen Situationen [The logic of failing. Strategic thinking in complex situations], Rowohlt, Hamburg.
[16] C.B. Handy (1983), Understanding organizations, Penguin Books Ltd, Harmondsworth.

[17] A. Hayashi, N. Ishii, M. Matsui (2009), “A Theory and Tools for Collaborative Demand-to-Supply Management in the SCM Age", Operations and Supply Chain Management, Vol. 2 No. 2, pp. 111-124.

[18] W. Bretzke (2010), Logistische Netzwerke [Logistic networks], Springer, Heidelberg Dordrecht London New York.

[19] E. Westkämper (2006), Einführung in die Organisation der Produktion [Introduction into production management], Springer, Berlin Heidelberg.

[20] T.P. Stank, P.J. Daugherty, A.E. Ellinger (1999), "Marketing/Logistics Integration and Firm Performance", The International Journal of Logistics Management, Vol. 10 No. 1, pp. 11-24.

[21] A.E. Ellinger (2000), "Improving Marketing/Logistics Cross-Functional Collaboration in the Supply Chain", Industrial Marketing Management, Vol. 29 No. 1, pp. 8596.

[22] B.P. Shapiro (1977), "Can marketing and manufacturing coexist?", Harvard Business Review, Vol. 44 No. 5, pp. 104-114.

[23] S.E. Fawcett, G.M. Magnan (2002),"The rhetoric and reality of supply chain integration", International Journal of Physical Distribution \& Logistics Management, Vol. 32 No. 5, pp. 339-361.

[24] H. Fastabend (1997), Kennliniengestützte Synchronisation von Fertigungs- und Montageprozessen [Curve-based synchronisation of productions], VDI, Düsseldorf.

[25] G. Zäpfel, B. Piekarz (1996), Supply Chain Controlling, Ueberreuter, Wien.

[26] R.P. Kampstra, J. Ashayeri, J.L. Gattorna (2006), "Realities of supply chain collaboration", The International Journal of Logistics Management, Vol. 17 No. 3, pp. 312-330.

[27] T.P. Stank, S.B. Keller, P.J. Daugherty (2001), "Supply chain collaboration and logistical service performance", Journal of Business Logistics, Volume 22 No. 1, pp. 29-48.

[28] T.M. Simatupang, R. Sridharan (2002), "The collaborative supply chain", The International Journal of Logistics Management, Vol. 13 No. 1, pp. 15-30.

[29] J.W. Forrester (1961), Industrial Dynamics, Productivity Press, Cambridge, MA.

[30] H.L. Lee, V. Padmanabhan, S. Whang (1997), "The bullwhip effect in supply chains", Sloan Management Review, Vol. 38 No. 3, pp. 93-102.

[31] M.L. Fisher (1997), "What is the right supply chain for your product?", Harvard Business Review, Vol. 75 No. 2, pp. 105-116.

[32] R.E. Spekman, J.W. Kamauff Jr., N. Myhr (1998): "An empirical investigation into supply chain management: a perspective on partnerships", Supply Chain Management: An International Journal, Vol. 3 No. 2, pp. 53-67.

[33] G. Schuh, T. Potente, R. Varandani, C. Hausberg, B. Fraenken (2014a), "Collaboration moves productivity to the 
next level", in Variety Management in Manufacturing. Proceedings of the 47th CIRP Conference on Manufacturing Systems, Procedia CIRP 17 (2014a), pp. 3-8.

[34] P.R. Lawrence, J.W. Lorsch (1969), Organization and environment, Richard D. Irwin, Inc., Homewood.

[35] A.E. Ellinger, P.J. Daugherty, S.B. Keller (2000), “The Relationship between Marketing/Logistics Interdepartmental Integration and Performance in U.S. Manufacturing Firms: An Empirical Study", Journal of Business Logistics, Vol. 21 No. 1, pp. 1-22.

[36] T.M. Simatupang, R. Sridharan (2005), "The collaboration index: a measure for supply chain collaboration", International Journal of Physical Distribution \& Logistics Management, Vol. 35 No. 1, pp. 44-62.

[37] S.W. Yoon, M. Matsui, T. Yamada, S.Y. Nof (2011) "Analysis of effectiveness and benefits of collaboration modes with information- and knowledge-sharing", Journal of Intelligent Manufacturing, Vol 22 No. 1, pp.101-112.

[38] P.R. Lawrence, J.W. Lorsch (1986), Organization and Environment: Managing Differentiation and Integration, Harvard Business School Press, Boston, MA.
[39] H. Mintzberg (1994), The Rise and Fall of Strategic Planning, Prentice Hall International (UK) Limited.

[40] M.E. Porter (1998), Competitive Strategy: Techniques for Analyzing Industries and Competitors, Free Press, New York.

[41] S. Mayer, E. Thiry, C.B. Frank, G. Kara, M. Alexander (2009): "Excellence in logistics. Supply chain during the crisis", published by A.T. Kearney. Available at: http://www.atkearney.com/images/global/ pdf/Excellence_in_Logistics.pdf (accessed 27 July 2015).

[42] P. Nyhuis, H.P. Wiendahl (2009), Fundamentals of Production Logistics. Theory, Tools and Applications, Springer, Berlin Heidelberg.

[43] G. Schuh, T. Potente, C. Wesch-Potente, A. Weber, J.P. Prote (2014b), "Collaboration Mechanisms to increase Productivity in the Context of Industrie 4.0", in Robust Manufacturing Conference (RoMaC 2014), Procedia CIRP 19, pp. 51-56.

[44] H. Kagermann, W. Wahlster, J. Helbig (2013), Recommendations for implementing the strategic initiative Industrie 4.0, Acatech., pp. 13-78. 